and L. A. Underkofler), on the role of starch in bread staling (C. W. Bice and W. P. Geddes) and on physical methods for the characterization of starches (C. C. Kesler and W. G. Bechtel). These two volumes bring together in convenient form a mass of carefully documented information concerning the fundamental chemistry and technology of starch and starch derivatives. Like the earlier editions, this one also will be of the greatest value to all concerned with the study or manufacture and use of these materials.

E. L. Hrast

\section{Chemistry of Carbon Compounds}

A Modern Comprehensive Treatise. Edited by Dr. E. H. Rodd. Vol. 2, Part A : Alicyclic Compounds. Pp. xxiii +488. (Amsterdam and New York: Elsevier Publishing Co. Inc.; London : Cleaver-Hume Press, Ltd., 1953.) 84s.

7 HIS volume fully maintains the high standard set in Vol. I (Nature, 170, 508; 1952). It is, however, more uniform in style, being largely the work of one author, Prof. R. A. Raphael, who has produced an excellent account of the chemistry, including the stereochemistry, of the various alicyclic types from single rings to polynuclear, condensed and bridged-ring systems and spiro compounds. Two short sections, on pyrethrins and hydnocarpic acids, are contributed by Dr. L. Crombie. Carotenoids are dealt with fully in a chapter by Dr. R. H. Hunter, and Dr. R. G. R. Bacon contributes a summary of polymeric derivatives of olefinic compounds, mainly rubber and rubber-like compounds, which are included here since the terpenes are included in Vol. $2 B$.

Like the previous volumes, this provides an authoritative source of accurate, detailed and up-todate information, and includes numerous references to the original literature and review articles.

\section{Buchanan}

\section{Kinetics and Mechanism}

A Study of Homogeneous Chemical Reactions. By Prof. Arthur A. Frost and Prof. Ralph G. Pearson. Pp. vii +343 . (Now York: John Wiley and Sons, Inc. ; London : Chapman and Hall, Ltd., 1953.) 48s. net.

7 HE authors state that there was need of a book giving an adequate account of the relations between kinetics and reaction mechanism, and they have attempted to fill this gap. There is no doubt that the result is satisfactory. It can serve as a text-book for advanced students, a guide to young lecturers, and a reference book which, since it contains bibliographies, will put the reader in touch with the literature. Although many of the examples are chosen from recent publications, the classical investigations, such as those of Harcourt and Esson, are by no means neglected, and it is clear that the authors have read and digested a wide field of literature, not confined to that published in the United States. There is an intelligible account of the transition-state theory, the rather difficult subject of complex reactions is dealt with systematically, and the recent investigations on the mechanism of organic reactions as elucidated by their kinetics are very well covered. Some parts, such as catalysis and chain reactions, are rather briefly considered, but there are other sources available for these. Since the mathematical parts are clearly set out, a student should not have much difficulty in following the text. This is a book which can be recommended.

J. R. Partington

\section{Changements de phases}

Comptes Rendus de la Deuxième Réunion Annuelle tenue en commun avec la Commission de Thermodynamique de l'Union Internationale de Physique, Paris, 2-7 Juin 1952. Pp. ix +487. (Paris: Société de Chimie Physique, 1952.) 3750 franes.

THIS volume contains no fewer than sixty-five papers on various aspects of its subject, and discussions on them. Some of the communications are short, and one consists of only sixteen lines. The subjects are arranged in eleven groups, namely, condensation, critical phenomena, phase equilibrium in solutions, solutions of polymers and colloids, co-operative phenomena in solids, polymorphism and rotation transitions, kinetics in solids, ferromagnetism and lambda-points, fusion, transitions in amorphous bodies, and transitions in surface phases. The papers are accompanied by short bibliographies. The collection will no doubt be very useful to those working in the field; but the treatment is, in general, too condensed to be easily understood by others, and it might have been better to have dealt with a more restricted field and to have had fewer papers. It would also have been useful to have included summarizing papers for each group, so that the general results of the work could be ascertained. The lack of agreement disclosed in the discussions is also confusing to those not actually working in this field. The discussion was probably of value to the participants; but the general reader may wish for a more homogeneous and critical survey of the important subject than is presented here.

\section{J. R. Partington}

\section{Data for X-Ray Analysis}

(Philips' Technical Library.) Vol. 1: Charts for Solution of Bragg's Equation ( $d$ versus $\Theta$ and $2 \Theta$ ). By W. Parrish and B. W. Irwin. Pp. vii +100 . Vol. 2 : Tables for Computing the Lattice Constant of Cubic Crystals. By W. Parrish, M. G. Ekstein, and B. W. Irwin. Pp. vii +81. (Eindhoven: N.V. Philips Gloeilampenfabrieken; London: CleaverHume Press, Ltd., 1953.) 15s. each.

TOL. 1 contains graphs of lattice spacing against

Bragg angle, covering a range from about $85^{\circ}$ down to low angles corresponding to spacings of $21 \mathrm{~A}$., for chromium, iron, cobalt and copper $K \alpha$ radiations ; the high angle limit is $40 \cdot 5^{\circ}$ for molybdenum. Spacings may be read to $0.01 \mathrm{~A}$. at low angles and, due to a change in scale, to $0.001 \mathrm{~A}$. at high angles, the $K \alpha_{1}$ and $K \alpha_{2}$ curves being plotted separately beyond a Bragg angle of $21^{\circ}$. The charts are intended for rapid determinations of lattice spacings in routine powder analysis, and they are admirably suited for this purpose. A still more open scale for lattice spacing might, however, have been used with some advantage at the very high angles, where the slope of the curves is sometimes as little as one part in forty.

The bulk of Vol. 2 consists of tables of $\frac{\lambda \sqrt{h^{2}+k^{2}+l^{2}}}{2}$

for the $K \alpha_{1}, K \alpha_{2}$ and $K \beta_{1}$ radiations of copper, nickel, cobalt, iron and chromium. The tables will shorten considerably the labour of calculating cubic lattice parameters, and, as they are given to six decimal places, they are suitable for work requiring high accuracy. Tables of $\sin ^{2} \theta$ and of the Nelson and Riley function $\frac{1}{2}\left(\frac{\cos ^{2} \theta}{\theta}+\frac{\cos ^{2} \theta}{\sin \theta}\right)$ are useful additions to the volume. A table of lattice constants of cubic 